\title{
Study of adverse effects of drought stress on two different hybrids of maize (Zea mays L.)
}

\author{
Muhammad Rashid, Mahmood Ahmad Sajid, Sibgha Noreen, Ahmed \\ Akrem, Seema Mahmood and Kausar Hussain Shah* \\ Institute of Pure and Applied Biology (IP\&AB), Bahauddin Zakariya University Multan, 60800-Multan- \\ Pakistan \\ *Corresponding author's email: kausar.shah@bzu.edu.pk \\ Citation \\ Muhammad Rashid, Mahmood Ahmad Sajid, Sibgha Noreen, Ahmed Akrem, Seema Mahmood and Kausar \\ Hussain Shah. Study of adverse effects of drought stress on two different hybrids of maize (Zea mays L.). Pure \\ and Applied Biology. Vol. 7, Issue 4, pp1316-1325. http://dx.doi.org/10.19045/bspab.2018.700153

\begin{tabular}{|c|c|c|c|}
\hline Received: $27 / 04 / 2018$ & Revised: $29 / 06 / 2018$ & Accepted: 30/08/2018 & Online First: 07/09/2018 \\
\hline
\end{tabular}

\section{Abstract}

Plants are exposed to various biotic and abiotic stresses. Some of the abiotic stresses are drought, salinity, extreme temperatures and pollutants. These stresses negatively affect plant growth and development. The present study was designed to investigate the effects of drought stress on biomass production and chlorophyll, proteins and proline contents of two different hybrids of maize plants (Zea mays L.). The experiment was conducted in randomized block design with four replicates in pots. Three weeks old plants were challenged with drought stress by skipping irrigation. After drought stress of two weeks the plants were harvested and were subjected to various morphometric, physiological and biochemical assays. Both hybrids exhibited significant reduction in biomass production under drought stress. However, this loss was relatively lower in hybrid M-32. Drought stress caused reduction in root and shoot length, chlorophyll contents and photosynthesis activity. The chlorophyll a/b ratio increased in hybrid M-435 under water deficit conditions. Contrastingly it was decreased in M-32 due to drought stress. The total soluble proteins (TSPs) and Proline concentration were greater in M-435 under drought conditions as compared to control. While M-32 exhibited relatively lower quantity of TSPs and Proline when grown under drought stress. The Proline concentration, TSPs and Chlorophyll a/b ratio was relatively higher in M-435 grown under drought stress that indicated its potential for drought tolerance. The current study revealed that maize plants may exhibit drought tolerance by adapting variations in their morphology, anatomical structures and metabolic and physiological profile.

Keywords: Abiotic stress; Chlorophyll contents; Drought stress; Maize; Proline; Zea mays

\section{Introduction}

Abiotic stresses like drought and salinity stress have major effect on crops. These stresses cause adverse effects on plant growth and development and reduce the plant yield [1]. Drought is one of the major abiotic stresses in the world and is rising due to climate change. Plants experience drought stress when the supply of water is reduced. It becomes a major problem, when the supply of water is impeded and transpiration rate is exceeded. Some plants may tolerate these stresses, but the extent of this tolerance depends on type of plants [2, 3, 4]. Drought stress is linked to other abiotic stresses like salinity, heat and cold stress. Water deficit imposes adverse effects on plants in terms of improper 
growth, reduced acquisition of nutrients and alteration in water status of plants [5, 6].

The difference in plant responses to drought stress seems to be due to differences in a variety of morphological, anatomical and physiological features. Some plants can modify their leaf structure in response to drought stress to reduce the transpiration rate [7]. They decrease stomatal conductance, turgor pressure and leaf water potential [8-10]. Due to such changes in chloroplast metabolism, the photosynthesis rate gets decreased [11].

It has been studied that chlorophyll $\mathrm{a}$ and $\mathrm{b}$ content play an important role in photosynthesis. The enhanced photosynthesis rate leads to increased crop growth and yield [12]. Drought not only disturb the chlorophyll content, but it also changes the chlorophyll ratio and total chlorophyll. It has been studied that under water deficit condition the chlorophyll $a, b$, total chlorophyll and chlorophyll ratio $(\mathrm{a} / \mathrm{b})$ is decreased [13-15]. The ratio of root to shoot length gets changed under the drought stress. These variations are accompanied by the changes in carbon and nitrogen metabolism [16]. The drought stress disturbs the biochemical pathways of plants. It decreases the efficiency of RUBISCO. In response to drought stress, plants accumulate stress-related metabolites like Glutathione, Glycine betaine and Polyamines. The increase in antioxidative enzymes like Superoxide Dismutase (SOD), Catalase (CAT), Ascorbate Peroxidase (APX), Peroxidase Dismutase (POD) and Glutathione Reductase (GR) also occurs. The molecular events like LEA (Late Embryogenesis Abundant), DSP (Dentine Sialoprotein) and RAB dehydrin can be exhibited by drought tolerant plants [13-15]. The plants under drought stress may accumulate the different type of essential inorganic nutrients such as Potassium, which may help in tolerance [16-18]. Furthermore, conventional breeding contributes in raising tolerant varieties. The cloning of resistance genes in crops to raise transgenic crops can be helpful in minimizing negative impacts of drought stress on growth and yield of crop plants [19].

The maize (Zea mays L.) is major C4 cereal crop. The plants are monoecious having separate male and female spikelets. The male spikelet is two-flowered. Each flower has three stamens, two lodicules, and a rudimentary pistil. The female spikelet is also two-flowered, but mostly, the lower flower is aborted [20]. Its production is approximately about 1021 million tons in 2014 [21]. It is predicted that maize will become top-ranked crop in 2020 in the world [22]. According to the U.S. USDA National Agricultural Statistics Service (Crop Production, March 2013), the US is largest producer and consumer of maize where it is cultivated in area about 84 million acres. It is largest domesticated grass in tropical Mexico (origin of maize). In Mexico, it is also used as model system for the analysis of organ development [23]. The China is second producer and consumer of maize worldwide [24]. Maize is not only used for feed and food, but it is also used for raw material in industry [25]. Maize is used as staple food in the world. The maize kernels contain about 70-75\% starch, $8-10 \%$ protein and $4-5 \%$ lipids. Prolamins is major (about $60 \%$ ) protein in kernel. This protein is also known as Zeins [26].

The present study was carried out to investigate the potential of two different hybrids of maize for drought tolerance along with biochemical and physiological changes in maize plants due to drought stress.

\section{Materials and methods}

The germplasm of two hybrids (M-32 and M-435) of maize (Zea mays L.) plants was obtained from Maize \& Millets Research Institute (MMRI) Yusafwala, Sahiwal, Pakistan. The experiments were conducted in a block design with four replicates at the Botanical Garden, Bahauddin Zakariya University Multan, Pakistan. The plants were grown for six weeks in pots filled with 
garden soil. The drought was applied by skipping normal irrigation after the establishment of the seedlings. After two weeks of drought stress, the plants were harvested to measure various morphometric, biochemical and physiological attributes.

\section{Length of root and shoot}

Length of root and shoot of each plant was measured by scale in $\mathrm{cm}$.

\section{Fresh biomass of root and shoot}

Roots and shoots of each plant were separated and were weighed in grams ( $\mathrm{g}$ ) by using digital microbalance (Shimadzu).

\section{Dry biomass of root and shoot}

For measuring dry weights of root and shoot the samples were placed in an oven for 7-10 days and their weights were measured in grams (g) by digital balance (Shimadzu).

\section{Chlorophyll contents}

Chlorophyll $(a, b)$ contents were measured by following the method of Arnon et al [27]. Fresh leaves $(1.0 \mathrm{~g})$ were ground in $80 \%$ acetone. The absorbance was measured by double beam spectrophotometer (Hitachi UV/VIS, U2900) at $645 \mathrm{~nm}$ and $663 \mathrm{~nm}$. The concentration of chlorophyll $a$ and $b$ were measured by following the equation by Arnon et al [27].

\section{Total soluble proteins (TSPs)}

Total soluble proteins were measured as described by Bradford [28]. Fresh leaf sample $(0.40 \mathrm{~g})$ was ground in $3 \mathrm{ml}$ of Sodium Phosphate buffer ( $\mathrm{pH}$ 6.8) and then centrifuged at $13000 \mathrm{rpm}$ for 15 minutes. The supernatant was obtained and stored in Eppendorf tubes for further use. The extracts were used for the determination of TSPs concentration. The samples were mixed with Bradford's reagent and absorbance was measured at $595 \mathrm{~nm}$ by using double beam spectrophotometer (Hitachi UV/VIS, U-2900).

\section{Proline contents}

The free proline was extracted from fresh leaves. About $0.20 \mathrm{~g}$ leaf sample was ground in 3\% (w/v) Sulfo-salicylic acid. It was estimated by using ninhydrin reagent according to the method of Bates \& Waldren [29]. The organic toluene phase containing the chromophore was separated and the absorbance of the developed red color was read at $520 \mathrm{~nm}$ by double beam spectrophotometer (Hitachi UV/VIS, U2900). By using calibration curve, proline concentration was calculated in MS-Excel.

\section{Statistical analysis}

MS-Excel (2013) was used to record the datasets and to calculate mean values, standard deviation and standard error. The software "Statistix 8.1" was used to do the analysis of variance (ANOVA) based on two factorial random design and to calculate the least significant difference (LSD) at $p<0.05$.

\section{Results}

The two hybrids of maize plants, M-435 and M-32 were grown under normal irrigation (control condition) and under drought stress by skipping normal irrigation. In both hybrids, the shoot length was greater in control as compared to drought stress. The shoot length of M-32 was greater under control condition as compared to M-435. Under drought stress, the shoot length of M-435 was greater than M-32 as shown in figure 1 (panel a). Both hybrids of maize showed decreased root length under drought condition, while under control condition the root length was relatively greater. The root length of M-32 was greater than the M-435 in control condition. While under drought stress, the root length of M-435 was greater than M32 as shown in figure 1 (panel b).

Under drought condition, the fresh weight of shoot was decreased in both hybrids. The M-435 had greater shoot fresh weight as compared to M-32 under drought stress. While under control condition, the M-435 had greater shoot fresh weight as compared to the M-32 as shown in figure 2 (panel a). The root fresh weight was decreased under drought stress. This loss was greater in M435 than M-32. The M-32 had greater root fresh weight as compared to M-435 in control condition as shown in figure 2 (panel b). The M-435 had greater shoot dry 
weight than M-32 under drought stress. Under control condition, M-32 had maximum shoot dry weight as shown in figure 2 (panel c). The root dry weight of both hybrids was greater as under control condition as compared to drought stress. The root dry weight in M-32 was greater as compared to M-435 under control condition as well as under drought stress as shown in figure 2 (panel d).

The amount of chlorophyll a in leaves of both hybrids of maize plants was greater under control condition as compared to drought stress. The M-32 plants showed higher contents of chlorophyll a as compared to M-435 under control condition as well as under drought stress as shown in figure 3 (panel a). The amount of chlorophyll $b$ of both hybrids was greater in control condition as compared to drought stress. The M-435 showed elevated amount of chlorophyll $\mathrm{b}$ under control condition. The amount of chlorophyll $b$ in hybrid M435 was greater under drought stress as compared to the M-32 under control and drought stress as shown in figure 3 (panel b). The chlorophyll ratio $\mathrm{a} / \mathrm{b}$ was greater in M-32 under control and drought stress as compared to M-435. The chlorophyll ratio of M-435 was greater under drought stress as compared to control condition. The chlorophyll ratio in M-32 was significantly greater in comparison to M-435 under drought stress as shown in figure 3 (panel c). The amount of total chlorophyll in both hybrids was significantly higher under control condition as compared to drought stress. The M-435 plants showed maximum chlorophyll content in comparison to M-32 grown under control condition. The amount of total chlorophyll in M-435 was higher under drought stress in comparison to M-32 however, this difference was statistically non-significant as shown in figure 3 (panel d).

The M-435 had highest concentration of total soluble proteins under drought stress, which is greater than control of same hybrid as well as the other hybrid (M-32) under control and drought stress. The M-32 had slightly greater contents of TSPs compared with M-435 under control condition. Similarly, M-32 had relatively greater amount of TSPs under drought stress than the M-435 hybrid under control condition but this difference was statistically nonsignificant as shown in figure 4 (panel a). The hybrid M-32 had significantly greater concentration of leaf proline in comparison with M-435 under control and drought condition. The hybrid M-32 had larger amount of leaf proline under control condition in comparison to drought stress. The hybrid M-435 had significantly lesser amount of proline under control condition as compared to drought stress as shown in figure 4 (panel b).

\section{Discussion}

Plants are exposed to a variety of biotic and/or abiotic stresses such as drought, salinity and extreme temperature that influence their development, growth and productivity [30]. Drought is one of the major abiotic stresses that severely affect and reduce the yield and productivity of food crops worldwide up to 70\% [31]. Maize (Zea mays L.) is the first staple cereal crop in the world [26]. The present study was conducted to investigate the plant biomass, proline contents, total soluble proteins and chlorophyll contents in maize under control and drought condition. Water deficit reduced the fresh as well as dry biomass of maize plants. It also reduced the shoot length, root length and chlorophyll contents. These findings are in-line with reports by Qadir et al [32], Ali et al [33] and Bibi et al [34].

Under drought condition, the shoot length of maize was decreased in comparison to control condition that corresponds to a study of drought stress in wheat cultivars [35]. The root and shoot biomass decrement was similar to a report by Boutraa et al observed by another study [36] in which the biomass was decreased in wheat plants under drought stress. 

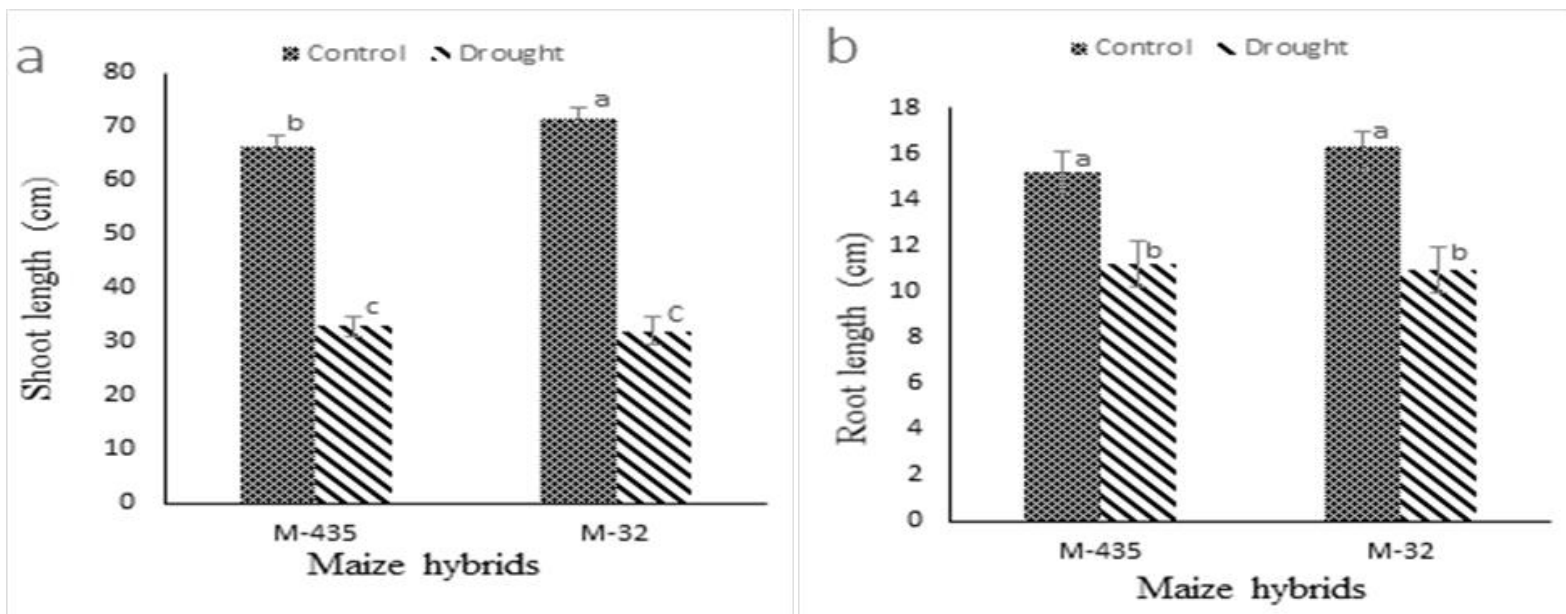

Figure 1. Shoot length (a) and Root length (b) of two different hybrids of maize (Zea mays L.) grown under control and drought conditions. Different letters shown on bars indicate the significant differences as calculated by LSD $(p<0.05 \%)$. The data presented are mean values \pm standard error of four replicates

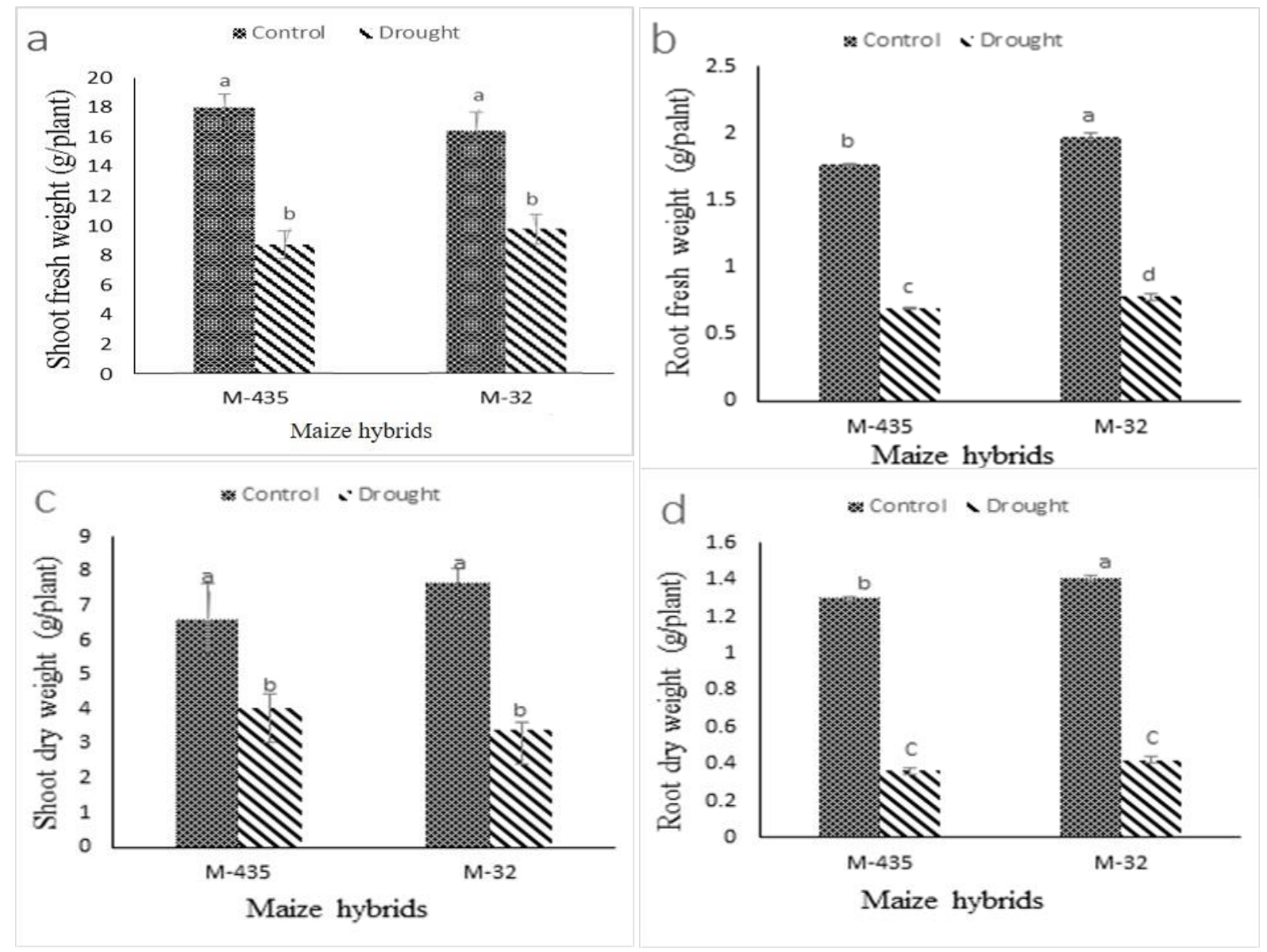

Figure 2. Shoot fresh weight (a), Root fresh weight (b), Shoot dry weight (c) and Root dry weight (d) of two different hybrids of maize (Zea mays L.) grown under control and drought conditions. Different letters shown on bars indicate the significant differences as calculated by LSD $(p<0.05 \%)$. The data presented are mean values \pm standard error of four replicates 


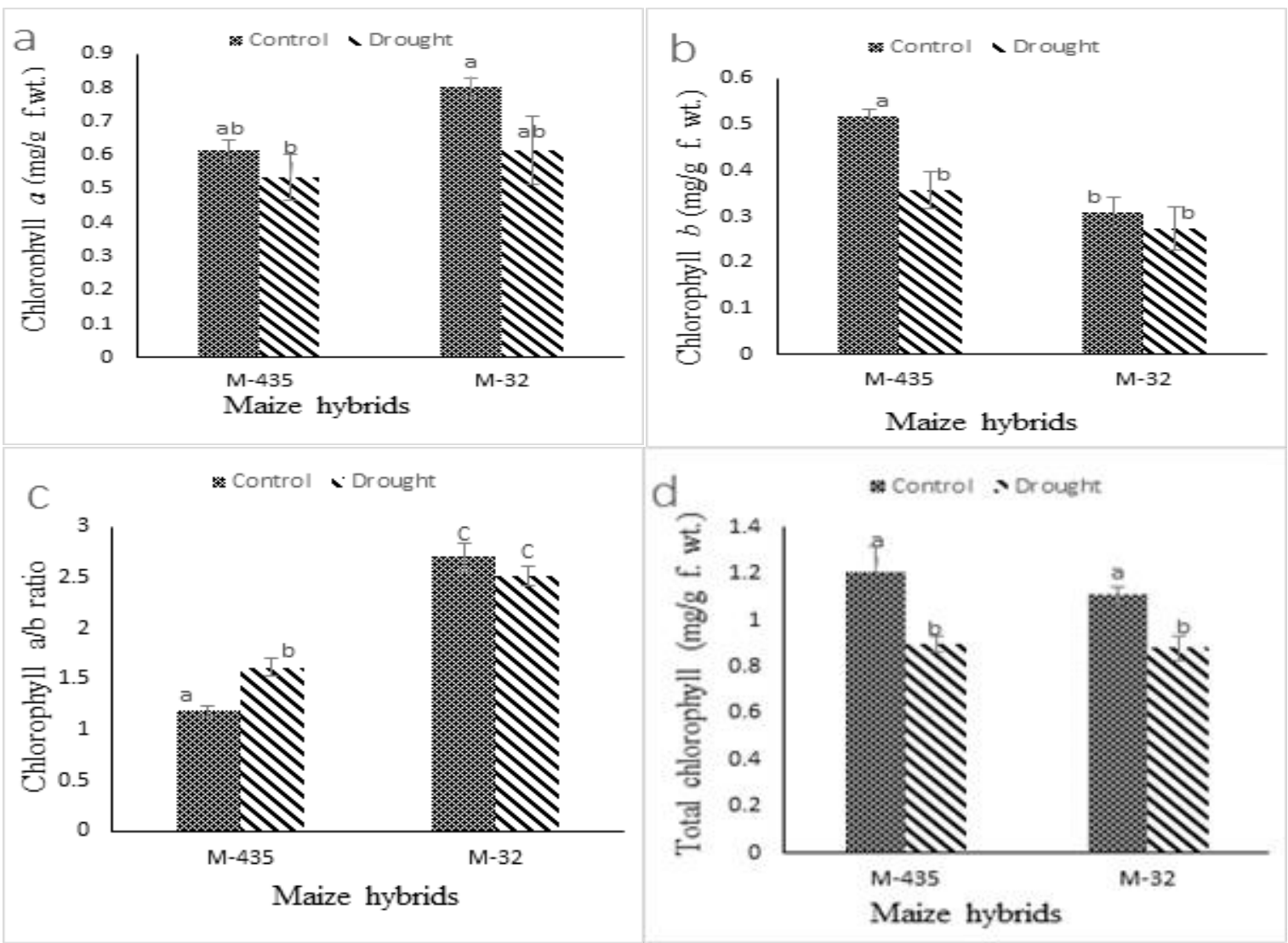

Figure 3. Chlorophyll a (a), Chlorophyll b (b), Chlorophyll a/b ratio (c) and Total Chlorophyll contents (d) of two different hybrids of maize (Zea mays L.) grown under control and drought conditions. Different letters shown on bars indicate the significant differences as calculated by LSD $(p<0.05 \%)$. The data presented are mean values \pm standard error of four replicates.
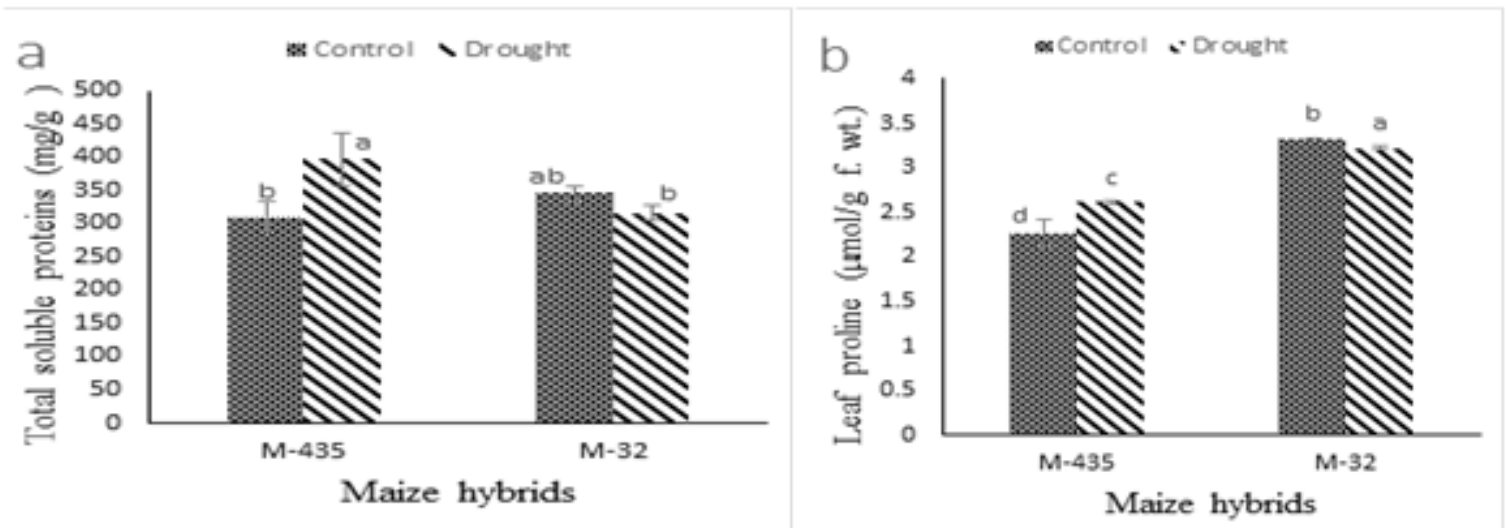

Figure 4. Total soluble proteins (a) and Leaf proline (b) of two different hybrids of maize (Zea mays $\mathrm{L}$.) grown under control and drought conditions. Different letters shown on bars indicate the significant differences as calculated by LSD $(p<0.05 \%)$. The dat a presented are $\mathrm{m}$ ean values \pm standard error of four replicates. 
Under drought stress, the root length was decreased as compared to control. In this study, it was observed that under water deficit condition the growth of root was negatively affected. The root and shoot fresh weight was decreased under stress condition. Similar report was published by Aldesuquy et al [37]. There is a report of biomass reduction in Sunflower [38], Soybean [39] and Poncirus trifoliatae [40] grown under drought stress. It was also decreased in common bean and green gram [41]. The reason of this decreased biomass may be the inhibitory effect of abscisic acid (ABA) which is induced by the water deficit condition in cells $[37,42]$.

The root and shoot dry weight were decreased under drought stress. This was also confirmed in wheat cultivars grown under drought stress in comparison to normal irrigation [30]. Similar results were found in Triticum durum by Boutraa et al. [36]. The root and shoot dry weight of Populus species was decreased under water deficit condition as reported by Wullschleger et al [43]. In another maize cultivar the shoot dry weight was decreased under drought stress [44].

The present study indicated that under drought condition the shoot and root length of maize gets decreased. Similar results were observed in some selected members of Triticales [45]. In Phaseolus acutifolius and $P$. vulgaris the shoot length was decreased under water deficit condition [46]. In other maize cultivars, the shoot length was decreased under drought stress in comparison with the control [44].

The current study indicated that under water deficit condition, total chlorophyll contents $(a, b)$ were decreased in maize. The chlorophyll $(\mathrm{a} / \mathrm{b})$ ratio was changed in M-435 grown under water deficit condition [47-49]. The chlorophyll contents were decreased under water deficit condition in Sunflower and in Vaccinium myrtillus [50]. Similarly, another study reported decreased chlorophyll contents in different wheat cultivars grown under drought stress [51].
The tolerant plants accumulate more proline under stress condition as compared to susceptible plants. According to Mohammadkhani \& Heidari [52] when maize was subjected to drought stress, it accumulated more proline as compared to control condition. In M-435 the increased contents of proline indicate its relatively higher potential of drought tolerance as compared to M-32. Similarly, the proline accumulation was higher in rice under water deficit condition [31]. Proline may reduce the water loss, or it may be helpful in plants to accumulate compatible solutes. Proline may supply energy for survival and growth under stress conditions. Thus, it may help the plant in tolerating the stress $[53,54]$.

The total soluble proteins in M-32 hybrid were decreased under drought stress in comparison to control condition. It is previously known that under water deficit conditions some proteases and/or catabolic enzymes might be produced which degrade the proteins. The decreased protein concentration may lead to oxidative stress in plants [55]. Another study reported that the total soluble proteins were decreased in wheat cultivars under drought stress [37].

\section{Conclusion}

Drought is a major problem for the crops and economy of the state. It is general observation that drought stress reduces the biomass production, free proline contents in leaves, TSPs, Chlorophyll contents and Photosynthesis activity in crop plants. In current study it was observed that the proline concentration, TSPs and chlorophyll a/b ratio was relatively higher in M-435 hybrid grown under drought stress as compared to the control conditions. From these findings it can be concluded that the maize hybrid M-435 has potential to grow under low moisture regimes. However, it may further be studied on molecular level to better understand the signaling pathway and mechanism of drought stress tolerance. 


\section{Authors' contributions}

Conceived and designed the experiments: KH Shah, Performed the experiments: M Rashid \& MA Sajid, Analyzed the data: S Noreen \& Seema Mahmood, Contributed materials/ analysis/tools: Seema Mahmood \& A Akrem, Wrote the paper: M Rashid \& MA Sajid.

\section{References}

1. Mahajan S \& Tuteja N (2005). Cold, salinity and drought stresses: an overview. Arch Biochem Biophy 444(2): 139-158.

2. Zhu JK (2002). Salt and Drought Stress Signal Transduction in Plants. Annu Rev Plant Biol 53: 247-273.

3. Chaitanya K, Jutur P, Sundar D \& Reddy AR (2003). Water stress effects on photosynthesis in different mulberry cultivars. Plant Growth Regul 40(1): 7580.

4. Andrews DJ \& Kumar KA, (1992) Pearl Millet for Food, Feed, and Forage. In: Donald LS, editor. Advances in Agronomy (Volume 48). Academic Press. pp 89-139.

5. Ali Q \& Ashraf M (2011). Induction of drought tolerance in maize (Zea mays L.) due to exogenous application of trehalose: growth, photosynthesis, water relations and oxidative defence mechanism. $J$ Agron Crop Sci 197(4): 258-271.

6. Shahbaz M, Iqbal M \& Ashraf M (2012). Response of differently adapted populations of blue panic grass (Panicum antidotale Retz.) to water defi cit conditions. J Appl Bot Food Qual 84(2): 134.

7. Hameed M, Batool S, Naz N, Nawaz T \& Ashraf M (2012). Leaf structural modifications for drought tolerance in some differentially adapted ecotypes of blue panic (Panicum antidotale Retz.). Acta Physiol Plant 34(4). 1479-1491.

8. Lawlor D \& Cornic G (2002). Photosynthetic carbon assimilation and associated metabolism in relation to water deficits in higher plants. Plant Cell Environ 25(2): 275-294.

9. Reddy AR, Chaitanya KV \& Vivekanandan M (2004). Droughtinduced responses of photosynthesis and antioxidant metabolism in higher plants. $J$ Plant Physiol 161(11): 1189-1202.

10. Shao HB, Chu LY, Jaleel CA \& Zhao CX (2008). Water-deficit stress-induced anatomical changes in higher plants. $C R$ Biol 331(3): 215-225.

11. Foryer C \& Noctor G (2000). Oxygen processing in photosynthesis: regulation and signaling. New Phytol 146: 359-388.

12. Taiz L \& Zeiger E (2006). Plant Physiology. 4th Ed. Sinauer Asociates Inc. Massachussets (USA).

13. Ashraf M, Azmi A, Khan A \& Nagvi S (1994). Water relations in different wheat (Triticum aestivum L.) genotypes under soil water deficits. Acta Physiol Plant 16(3): 231-240.

14. Massacci A, Nabiev S, Pietrosanti L, Nematov S, Chernikova T, Thor K \& Leipner J (2008). Response of the photosynthetic apparatus of cotton (Gossypium hirsutum) to the onset of drought stress under field conditions studied by gas-exchange analysis and chlorophyll fluorescence imaging. Plant Physiol Biochem 46(2): 189-195.

15. Hamayun M, Khan SA, Shinwari ZK, Khan AL, Ahmad N \& Lee I-J (2010). Effect of Polyethylene Glycol induced drought stress on physio-hormonal attributes of Soybean. Pak J Bot 42(2): 977-986.

16. Noctor G, Gomez L, Vanacker H \& Foyer $\mathrm{CH}$ (2002). Interactions between biosynthesis, compartmentation and transport in the control of glutathione homeostasis and signalling. $J$ Exper Bot 53(372): 1283-1304.

17. Akram NA, Shahbaz $M$ \& Ashraf $M$ (2008). Nutrient acquisition in differentially adapted populations of Cynodon dactylon (L.) Pers. and Cenchrus ciliaris L. under drought stress. Pak J Bot 40(4): 1433-1440.

18. FAO (2016). Food and Agriculture Organization of the United Nations.

19. Blum A (2005). Drought resistance, wateruse efficiency, and yield potential- are they compatible, dissonant, or mutually exclusive? Crop Pasture Sci 56(11): 11591168.

20. Rajaram V, Nepolean T, Senthilvel S, Varshney RK, Vadez V, Srivastava RK, Shah TM, Supriya A, Kumar S, Kumari BR, Bhanuprakash A, Narasu ML, RieraLizarazu O \& Hash CT (2013). Pearl millet [Pennisetum glaucum (L.) R. Br.] consensus linkage map constructed using four RIL mapping populations and newly 
developed EST-SSRs. BMC Genom 14(1): 159.

21. Balsanelli E, Tadra-Sfeir MZ, Faoro H, Pankievicz VCS, de Baura VA, Fábio O Pedrosa FO, de Souza EM \& Monteiro RDRA (2016). Molecular adaptations of Herbaspirillum seropedicae during colonization of the maize rhizosphere. Environ Microbiol 18(8): 2343-2356.

22. Wang Z, Han L, Suna K, Jin J, Ro KS, Libra JA, Liu X \& Xing B (2016). Sorption of four hydrophobic organic contaminants by biochar derived from maize straw, wood dust and swine manure at different pyrolytic temperatures. Chemosphere 144: 285-291.

23. Deng Z, Wang Z-Y \& Kutschera U (2016). Seedling development in maize cv. B73 and blue light-mediated proteomic changes in the tip vs. stem of the coleoptile. Protoplasma 1-6.

24. Anjum SA, Tanveer M, Hussain S, Bao M, Wang L, Khan I, Ullah E, Tung SA, Samad RA \& Shahzad B (2015). Cadmium toxicity in Maize (Zea mays L.): consequences on antioxidative systems, reactive oxygen species and cadmium accumulation. Environ Sci Pollut Res 22(21): 17022-17030.

25. Li P, Zhuang Z, Li P, Zhuang Z, Cai H, Cheng S, Soomro AA, Liu Z, Gu R, Mi G, Yuan L \& Chen F (2016). Use of genotype-environment interactions to elucidate the pattern of maize root plasticity to nitrogen deficiency. J Integr Plant Biol 58(3): 242-253.

26. Yao D, Qi W, Xia Li X, Yang Q, Yan S, Ling $\mathrm{H}$, Wang $\mathrm{G}$, Wang $\mathrm{G}$ \& Song $\mathrm{R}$ (2016). Maize opaque10 encodes a cerealspecific protein that is essential for the proper distribution of Zeins in endosperm protein bodies. PLOS Genet 12(8): e1006270.

27. Arnon DI, Allen M \& Whatley F (1956). Photosynthesis by isolated chloroplasts IV. General concept and comparison of three photochemical reactions. Biochimica et Aiophysica Acta. 20: 449-461.

28. Bradford MM (1976). A rapid and sensitive method for the quantitation of microgram quantities of protein utilizing the principle of protein-dye binding. Anal Biochem 72: 248-254.

29. Bates L, Waldren R \& Teare I (1973). Rapid determination of free proline for water-stress studies. Plant Soil 39(1): 205207.

30. Abdalla M \& El-Khoshiban N (2007). The influence of water stress on growth, relative water content, photosynthetic pigments, some metabolic and hormonal contents of two Triticium aestivum cultivars. J Appl Sci Resear 3(12): 20622074.

31. Lum MS, Hanafi MM, Rafii YM, Akmar ASN (2014). Effect of drought stress on growth, proline and antioxidant enzyme activities of upland rice. J Anim Plant Sci 24(5): 1487-1493.

32. Qadir M, Bibi A, Tahir MHN, Saleem M \& Sadaqat HA (2015). Screening of Sorghum (Sorghum bicolor L) genotypes under various levels of drought stress. Maydica 60(4): M35.

33. Ali MA, Abbas A, Awan SI, Jabran K, Gardezi SDA (2011). Correlated response of various morpho-physiological characters with grain yield in sorghum landraces at different growth phases. $J$ Anim Plant Sci 21(4): 671-679.

34. Bibi A, Sadaqat HA, Tahir MHN \& Akram H (2012). Screening of Sorghum (Sorghum bicolor var Moench) for drought tolerance at seedling stage in Polyethylene Glycol. J Anim Plant Sci 22(3): 671-678.

35. Aldesuquy HS, Abo-hamed SA, Abbas MA \& Elhakem AH (2012). Role of Glycine Betaine and Salicylic acid in improving growth vigour and physiological aspects of droughted Wheat cultivars. J Stress Physiol Biochem 8(10): 149-171.

36. Boutraa T, Akhkha A, Al-Shoaibi AKA \& Alhejeli AM (2010). Effect of water stress on growth and water use efficiency (WUE) of some Wheat cultivars (Triticum durum) grown in Saudi Arabia. J Taib Uni Sc 3: 39-48.

37. Aldesuquy HS, Ibraheem FI \& Gahnem HE (2014). Comparative morphobiochemical responses of wheat cultivars sensitive and tolerant to water stress. $J$ Stress Physiol Biochem 10(2): 168-189.

38. Tahir MHN \& Mehdi SS (2001). Evaluation of open pollinated Sunflower (Helianthus annuus L.) populations under water stress and normal conditions. Int $J$ Agric Biol 3(2): 236-238.

39. Specht JE, Chase K, Macrander M, Graef GL, Chung J, Markwell JP, Germann M, 
Orf JH \& Lark KG (2001). Soybean response to water: A QTL analysis of drought tolerance. Crop Sci 41: 493-509.

40. Wu Q-S, Xia R-X \& Zou Y-N (2008). Improved soil structure and citrus growth after inoculation with three arbuscular mycorrhizal fungi under drought stress. Eur J Soil Biol 44(1): 122-128.

41. Webber M, Barnett J, Finlayson B \& Wang M (2008). Pricing China's irrigation water. Glob Environ Chang 18(4): 617625.

42. Hassanein A (2000). Physiological responses induced by shock and gradual salinization in Rice (Oryza sativa L.) seedlings and the possible roles played by Glutathione treatment. Acta Bot Hung 42: 139-159.

43. Wullschleger SD, Yin TM, DiFazio SP, Tschaplinski TJ, Gunter LE, Davis MF \& Tuskan GA (2005). Phenotypic variation in growth and biomass distribution for two advanced-generation pedigrees of hybrid poplar. C J Forest Res 35(8): 1779-1789.

44. Khan IA, Habib S, Sadaqat HA \& Tahir MHN (2004). Selection criteria based on seedling growth parameters in maize varies under normal and water stress conditions. Int J Agric Biol 6: 252-256.

45. Kaydan D \& Yagmur M (2008). Germination, seedling growth and relative water content of shoot in different seed sizes of Triticale under osmotic stress of water and $\mathrm{NaCl}$. Afri J Biotech 7: 2862.

46. Türkan I, Bor M, Özdemir F \& Koca H (2005). Differential responses of lipid peroxidation and antioxidants in the leaves of drought-tolerant $P$. acutifolius Gray and drought-sensitive $P$. vulgaris $\mathrm{L}$. subjected to polyethylene glycol mediated water stress. Plant Sci 168(1): 223-231.

47. Anjum F, Yaseen M, Rasool E \& Wahid A (2003). Water stress in barley (Hordeum vulgare L.). II. Effect on chemical composition and chlorophyll contents. Pak J Agric Sci 40: 45-49.
48. Farooq M, Wahid A, Kobayashi N, Fujita D \& Basra SMA (2009). Plant drought stress: effects, mechanisms and management. Agr Sust Devel 29(1): 185212.

49. Jaleel CA, Manivannan P, Wahid A, Farooq M, Al-Juburi HJ, Somasundaram R \& Panneerselvam R (2009). Drought stress in plants: a review on morphological characteristics and pigments composition. Int J Agric Biol 11(1): 100-105.

50. Tahkokorpi M, Taulavuori K, Laine K, Taulavuori E (2007). After-effects of drought-related winter stress in previous and current year stems of Vaccinium myrtillus L. Environ Exper Bot 61(1): 8593.

51. Valifard M, Moradshahi A \& Kholdebarin B (2012). Biochemical and physiological responses of two wheat (Triticum aestivum L.) cultivars to drought stress applied at seedling stage. J Agri Sci Techn 14: 15671578.

52. Mohammad KN \& Heidari R (2008). Drought-induced accumulation of soluble sugars and proline in two maize varieties. World Appl Sci J 3: 448-453.

53. Ashraf M \& Foolad M (2007). Roles of glycine betaine and proline in improving plant abiotic stress resistance. Environ Exper Bot 59: 206-216.

54. Anjum SA, Ashraf U, Tanveer M, Khan I, Hussain S, Shahzad B, Zohaib A, Abbas F, Saleem MF, Ali I \& Wang LC (2017). Drought induced changes in growth, osmolyte accumulation and antioxidant metabolism of three maize hybrids. Front Plant Sci 8: 69.

55. Mafakheri A, Siosemardeh A, Bahramnejad B, Struik PC \& Sohrabi Y (2011). Effect of drought stress and subsequent recovery on protein, carbohydrate contents, catalase and peroxidase activities in three Chickpea (Cicer arietinum) cultivars. Austr J Crop Sci 5(10): 1255-1260. 